(c) American Dairy Science Association, 2004.

\title{
Iron Uptake by Escherichia coli Cultured with Antibodies from Cows Immunized with High-Affinity Ferric Receptors*
}

\section{S. L. Wolf, J. S. Hogan, and K. L. Smith}

Department of Animal Sciences, The Ohio State University,

Ohio Agricultural Research and Development Center, Wooster 44691

\begin{abstract}
The synergistic effects of immunoglobulin G ( $\operatorname{IgG}$ ) from cows vaccinated with ferric citrate receptor (FecA) and IgG from cows vaccinated with ferric enterobactin receptor (FepA) were measured in an in vitro iron uptake assay. Serum was isolated and pooled within treatment from five cows each vaccinated with FepA or FecA or not vaccinated. Immunoglobulin $\mathrm{G}$ was isolated by ammonium sulfate precipitation and protein $\mathrm{G}$ affinity chromatography. Six Escherichia coli isolates from bovine intramammary infections were cultured in an irondepleted medium to induce high-affinity iron acquisition systems and, in iron-depleted conditions, to specifically induce the expression of FecA. The bacterial cells were mixed with either 3 or $6 \mathrm{mg} / \mathrm{mL}$ of purified IgG and ${ }^{55} \mathrm{Fe}$. The radioactivity of ${ }^{55} \mathrm{Fe}$ taken up by the bacterial cells was measured by a liquid scintillation counter after 5-, 10-, and 15 -min incubations at $37^{\circ} \mathrm{C}$. The combination of anti-FecA IgG and anti-FepA IgG reduced ${ }^{55} \mathrm{Fe}$ uptake compared with either anti-FecA or anti-FepA alone. Iron uptake was reduced more by anti-FecA IgG than by anti-FepA IgG when the ferric citrate system was induced. Reduction of iron uptake did not differ between anti-FepA alone and anti-FecA alone when citrate was absent from the medium.
\end{abstract}

(Key words: Escherichia coli, FecA, FepA, immunoglobulin G)

Abbreviation key: FecA = ferric citrate receptor, FepA = ferric enterobactin receptor, IROMP = ironregulated outer membrane proteins.

\section{INTRODUCTION}

Iron-regulated outer membrane proteins (IROMP) are commonly expressed by Escherichia coli isolated from bovine IMI. The IROMP are appealing candidates

Received October 6, 2003.

Accepted February 20, 2004

Corresponding author: J. S. Hogan; e-mail: hogan.4@osu.edu.

*Salaries and research support were provided by State and Federal funds appropriated to the Ohio Agricultural Research and Development Center, The Ohio State University. Manuscript No. 14-04AS. as vaccine antigens because they are surface-exposed, antigenic, and may induce production of antibodies to block uptake of iron into the bacterial cell (Todhunter et al., 1991). Antigenic properties of receptor proteins are highly conserved within members of Enterobacteriaceae (Chart and Griffiths, 1985). The high-affinity iron acquisition systems rely upon receptors such as FecA, which recognizes the ferric citrate complex, and FepA, which binds ferric enterobactin. These receptor proteins are expressed on the surface of $E$. coli in iron-limiting conditions (Neilands, 1982, 1994; Hantke, 2001). Available iron in mammalian tissue is severely restricted. Therefore, the induction of high-affinity iron uptake systems using IROMP to bind ferric complexes is essential for coliform organisms to obtain their iron requirement in the restricted conditions in the bovine mammary gland.

Several studies have shown that antibodies to IROMP have reduced the uptake of iron by blocking the binding of ferric complexes (Murphy et al., 1990; Zhou et al., 1995; Takemura et al., 2003). Results from a study by Lin et al. (1999b) showed that polyclonal IgG from FepA-immunized cows inhibited growth of $E$. coli from coliform IMI. Purified IgG, isolated from FecA immunized cows, reduced iron uptake by $E$. coli (Takemura et al., 2003). However, the antibody did not completely inhibit the transport of iron into the cell (Takemura et al., 2003).

The ferric enterobactin and ferric citrate iron transport systems can operate simultaneoulsly in wild-type E. coli cells (Frost and Rosenberg, 1973). Therefore, antibodies targeted at one system would still allow for transport of iron through remaining systems. Vaccines targeting multiple iron-transport systems could potentially be effective at starving $E$. coli cells of their iron requirement, thus preventing growth in the mammary gland. The objective of the current study was to determine the in vitro synergistic effects of IgG directed against FecA and FepA on inhibiting iron uptake by $E$. coli isolated from bovine intramammary infections.

\section{MATERIALS AND METHODS}

\section{Sources of Anti-FecA and Control Immunoglobulin}

Ten gravid Holstein heifers from the Ohio Agricultural Research and Development Center were assigned 
to 5 pairs of animals. Animals were paired by anticipated calving date. Heifers within the blocks were randomly assigned to 1 of 2 treatments: 1) FecA immunization or 2) unvaccinated control. FecA antigen was isolated from $E$. coli UT5600/pSV66 (Lin et al., 1999a) grown in trypticase soy broth containing $200 \mu M \alpha-\alpha^{\prime}-$ dipyridyl (Sigma Chemical Co., St. Louis, Mo.) and 1 $\mathrm{m} M$ citrate. The FecA vaccine consisted of $400 \mu \mathrm{g}$ of antigen in $5 \mathrm{~mL}$ of PBS, emulsified in $5 \mathrm{~mL}$ of Freund's incomplete adjuvant (Difco Laboratories, Detroit, MI), so that $10-\mathrm{mL}$ subcutaneous injections were administered posterior to the scapula. Vaccinated heifers received a primary immunization and boosters 14, 28, and $42 \mathrm{~d}$ later.

A total of $100 \mathrm{~mL}$ of blood were collected from each heifer $63 \mathrm{~d}$ after the primary immunizations from both vaccinated and control groups. Serum was collected from d-63 samples and pooled within treatment groups. Using methods described previously by Lin et al. (1999b), immunoglobulin G was purified from pooled serum by ammonium sulfate precipitation followed by protein $\mathrm{G}$ affinity chromatography.

\section{Source of Anti-FepA Immunoglobulin G}

Anti-FepA IgG was isolated and purified by Lin et al. (1999b). Cows were vaccinated with 100 or $500 \mu \mathrm{g}$ of FepA protein suspended in $5 \mathrm{~mL}$ of PBS and $5 \mathrm{~mL}$ of Freund's incomplete adjuvant. Cows received a primary immunization at $200 \mathrm{DIM}$ and booster immunizations 14 and $28 \mathrm{~d}$ later. Immunoglobulin $\mathrm{G}$ responses did not differ between doses; therefore, serum samples from d 35 following primary immunization were pooled and used for IgG purification (Lin et al., 1999b). Anti-FepA IgG was stored at $-70^{\circ} \mathrm{C}$ until used in the assays.

\section{Antibody Titers}

Antibody titers to FepA and FecA proteins were determined by ELISA (Lin et al., 1998a) for pooled IgG samples from FecA-immunized heifers, control heifers, and FepA-immunized cows. Purified IgG concentration used to determine antibody titers to FecA and FepA was $4 \mathrm{mg} / \mathrm{mL}$ diluted in PBS. The coating antigens were purified FecA or FepA.

\section{Iron Transport Assays}

Nonspecific induction of high-affinity iron acquisition systems. Six $E$. coli isolates from cases of naturally occurring IMI were tested under culture conditions known to induce high-affinity iron acquisition systems. Each isolate had previously been shown to express both FecA and FepA following culture in vitro
(Lin et al., 1998b; 1999a). Bacteria were stored in trypticase soy broth containing $20 \%$ glycerine at $-70^{\circ} \mathrm{C}$. Escherichia coli were grown to mid-log phase in $10 \mathrm{~mL}$ of chemically defined medium (Bacto-Synthetic broth, Difco Laboratories) for $18 \mathrm{~h}$ at $37^{\circ} \mathrm{C}$ and $200 \mathrm{rpm}$. The cells were washed twice and resuspended to the original volume in PBS with $200 \mu M \alpha$ - $\alpha^{\prime}$-dipyridyl. A 2-mL portion of the washed cells was inoculated into $10 \mathrm{~mL}$ of the chemically defined medium plus $200 \mu M \alpha-\alpha^{\prime}-$ dipyridyl and incubated for $3 \mathrm{~h}$ at $37^{\circ} \mathrm{C}$ and $200 \mathrm{rpm}$. The cells were centrifuged and washed twice in PBS with $200 \mu M \alpha$ - $\alpha^{\prime}$-dipyridyl. The cells were resuspended to approximately $10^{7}$ cells $/ \mathrm{mL}$ in uptake medium (Hussein et al., 1981). The bacterial suspension was serially diluted in PBS, spotted on MacConkey agar plates, and incubated for $12 \mathrm{~h}$ at $37^{\circ} \mathrm{C}$ for determining cfu/mL.

The bacterial suspension $(1.25 \mathrm{~mL})$ was incubated for $30 \mathrm{~min}$ on ice with $1.1 \mathrm{~mL}$ of antibody dilution in $10 \times 75$-mm polystyrene culture tubes. Five antibody treatments were used in dilutions for final assay concentrations: 1) control IgG (3 mg/mL), 2) anti-FecA IgG $(3 \mathrm{mg} / \mathrm{mL}), 3)$ anti-FepA IgG $(3 \mathrm{mg} / \mathrm{mL}), 4)$ both antiFepA $(3 \mathrm{mg} / \mathrm{mL})$ and anti-FecA IgG $(3 \mathrm{mg} / \mathrm{mL})(6 \mathrm{mg} / \mathrm{mL}$ total), and 5) PBS $(0 \mathrm{mg} / \mathrm{mL})$ as a negative control. Nitrilotriacetate $(0.1 \mathrm{mM})$ was added to the assay to suppress non-specific iron uptake and incubated at $37^{\circ} \mathrm{C}$ for $5 \mathrm{~m}$ (Takemura et al., 2003). The ${ }^{55} \mathrm{Fe}$ cocktail was added to the assay at final concentrations of $10 \mu M$ $\mathrm{FeCl}_{3}, 100 \mu M$ soduim citrate, and $0.2 \mu \mathrm{Ci}{ }^{55} \mathrm{Fe} / \mathrm{mL}$ $\left(\sim 0.05 \mu M{ }^{55} \mathrm{Fe}\right)$ and incubated on a dry block heater at $37^{\circ} \mathrm{C}$. Testing procedures were those described by Takemura et al. (2003). The iron transport assay was repeated twice for each $E$. coli isolate. The measurements were expressed as the number of ${ }^{55} \mathrm{Fe}$ atoms taken up per colony-forming unit, and then transformed to $\log _{10}$ for statistical analysis.

Induction of FecA. Iron uptake by $E$. coli isolates was tested in Fe-depleted conditions to selectively induce the expression of FecA (Hussein et al., 1981). Culture medium was the chemically defined medium containing $200 \mu M \alpha$ - $\alpha^{\prime}$-dipyridyl and $1 \mathrm{~m} M$ citrate. Bacteria were washed in PBS with $200 \mu M \alpha$ - $\alpha^{\prime}$-dipyridyl and $1 \mathrm{~m} M$ citrate. Other experimental factors including bacterial isolates, IgG treatments, and incubation conditions were those described previously for testing isolates in culture conditions to induce high-affinity iron acquisition systems.

Synergistic effects of IgG. The possible synergistic effects of different combinations of IgG from the three treatment groups on iron uptake were measured in conditions that selectively induced the expression of FecA. Cells were washed in a $1-\mathrm{m} M$ solution of citrate and inoculated into $10 \mathrm{~mL}$ of chemically defined medium containing $200 \alpha M \alpha$ - $\alpha^{\prime}$-dipyridyl and $1 \mathrm{~m} M$ citrate. 
Six antibody treatments were used with final assay concentrations of $6 \mathrm{mg} / \mathrm{mL}$ : 1) anti-FepA IgG, 2) antiFecA IgG, 3) both anti-FepA (3 mg/mL) and anti-FecA IgG ( $3 \mathrm{mg} / \mathrm{mL}), 4)$ both anti-FepA $(3 \mathrm{mg} / \mathrm{mL})$ and control IgG (3 mg/mL), 5) both anti-FecA $(3 \mathrm{mg} / \mathrm{mL})$ and control IgG $(3 \mathrm{mg} / \mathrm{mL})$, and 6) PBS $(0 \mathrm{mg} / \mathrm{mL})$ as a negative control. Other experimental factors including bacterial isolates and incubation conditions were described previously for testing isolates in culture conditions to induce the expression of FecA.

\section{Statisical Analysis}

Differences among treatments for $\log _{10}{ }^{55} \mathrm{Fe}$ atoms/ cfu were tested by least squares ANOVA (SAS Inst., Inc., Cary, NC). The variables were tested for treatment effects within sample time. The variables were also tested for treatment effects partitioned into multiple contrasts. Preplanned contrasts among treatments for synergistic effects of IgG included 1) IgG vs. negative control; 2) immunized IgG vs. control IgG; 3) anti-FecA vs. anti-FepA IgG; 4) anti-FecA/anti-FepA IgG combination vs. other treatments with FecA IgG; and 5) antiFecA/anti-FepA IgG combination vs. other treatments with anti-FepA IgG.

\section{RESULTS}

\section{Immunoglobulin G Titers}

Immunoglobulin $G$ titers against FecA were 1:160,000 for IgG from heifers immunized with FecA; 1:5,120 for IgG from cows immunized with FepA; and $1: 1,280$ for IgG from unvaccinated control heifers. Immunoglobulin $\mathrm{G}$ titers against FepA were 1:160,000 for IgG from cows immunized with FepA; 1:5,120 for cows immunized with FecA; and 1:2,560 for IgG from unvaccinated control heifers.

\section{Iron Transport Assays}

Nonspecific induction of high-affinity iron acquisition systems. The presence of IgG decreased iron uptake compared with PBS only (Figure 1). Uptake of ${ }^{55} \mathrm{Fe}$ was comparable between anti-FepA and anti-FecA treatments $(P>0.05)$. The combination of anti-FecA/ anti-FepA IgG reduced iron transport at $5 \mathrm{~min}$ compared with anti-FepA IgG alone $(P<0.001)$, control IgG $(P<0.01)$, and anti-FecA IgG $(P=0.09)$. After a 10 min incubation, the combination of anti-FecA/antiFepA IgG significantly reduced iron transport into the $E$. coli cells compared with anti-FepA IgG $(P<0.05)$. The combined effects of both anti-FecA and anti-FepA IgG had greater reduction in iron transport than either treatment alone after $5 \mathrm{~min}$.

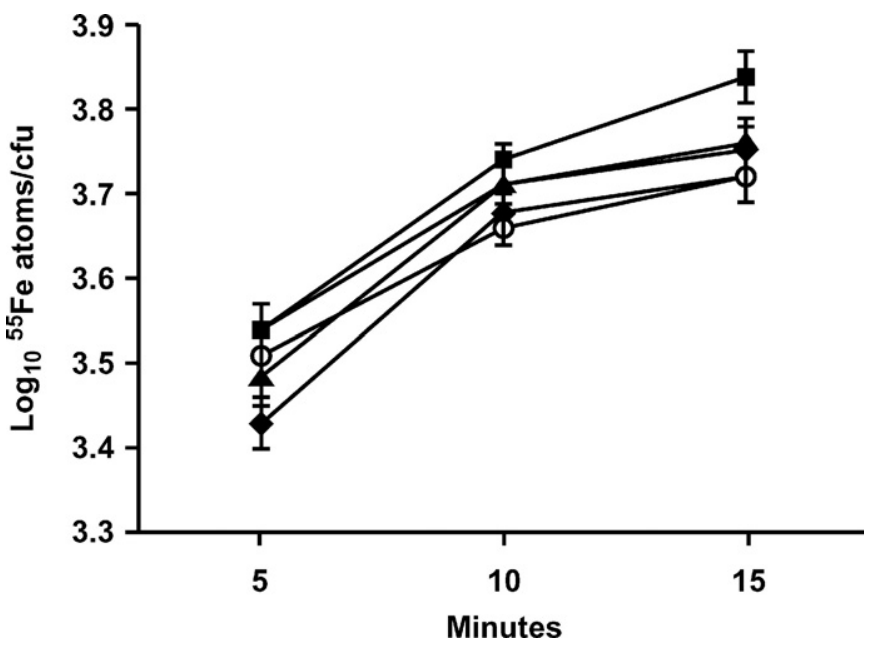

Figure 1. Mean number of ${ }^{55} \mathrm{Fe}$ atoms taken up by Escherichia coli $(\mathrm{n}=6)$ tested under culture conditions known to induce highaffinity iron acquisition systems. Isolates were grown in the presence of $3 \mathrm{mg} / \mathrm{mL}$ of control IgG (A), $3 \mathrm{mg} / \mathrm{mL}$ of anti-FepA IgG (-), $3 \mathrm{mg} /$ $\mathrm{mL}$ of anti-FecA IgG (O), $3 \mathrm{mg} / \mathrm{mL}$ of anti-FepA and $3 \mathrm{mg} / \mathrm{mL}$ of antiFecA IgG ( ), and PBS without IgG (ם). Dispersion bars represent standard errors of the mean.

Induction of FecA. The presence of IgG decreased iron uptake compared with no IgG treatment $(P<0.01$; Figure 2). The uptake of ${ }^{55} \mathrm{Fe}$ was reduced in the presence of anti-FecA IgG compared with anti-FepA IgG after a $10-\min$ incubation $(P<0.05)$. The combination of anti-FecA/anti-FepA IgG reduced iron uptake com-

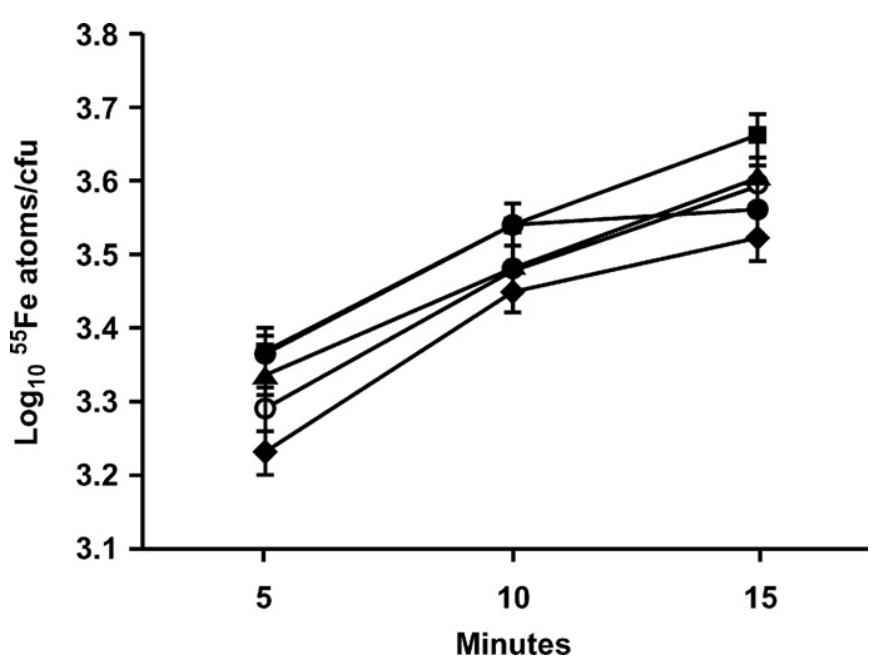

Figure 2. Mean number of ${ }^{55} \mathrm{Fe}$ atoms taken up by Escherichia $\operatorname{coli}(\mathrm{n}=6)$ tested under conditions to selectively induce the expression of FecA. Isolates were grown in the presence of $3 \mathrm{mg} / \mathrm{mL}$ of control IgG (४), $3 \mathrm{mg} / \mathrm{mL}$ of anti-FepA IgG (৩), $3 \mathrm{mg} / \mathrm{mL}$ of anti-FecA IgG (O), $3 \mathrm{mg} / \mathrm{mL}$ of anti-FepA and $3 \mathrm{mg} / \mathrm{mL}$ of anti-FecA IgG ( ), and PBS without IgG (ם). Dispersion bars represent standard errors of the mean. 


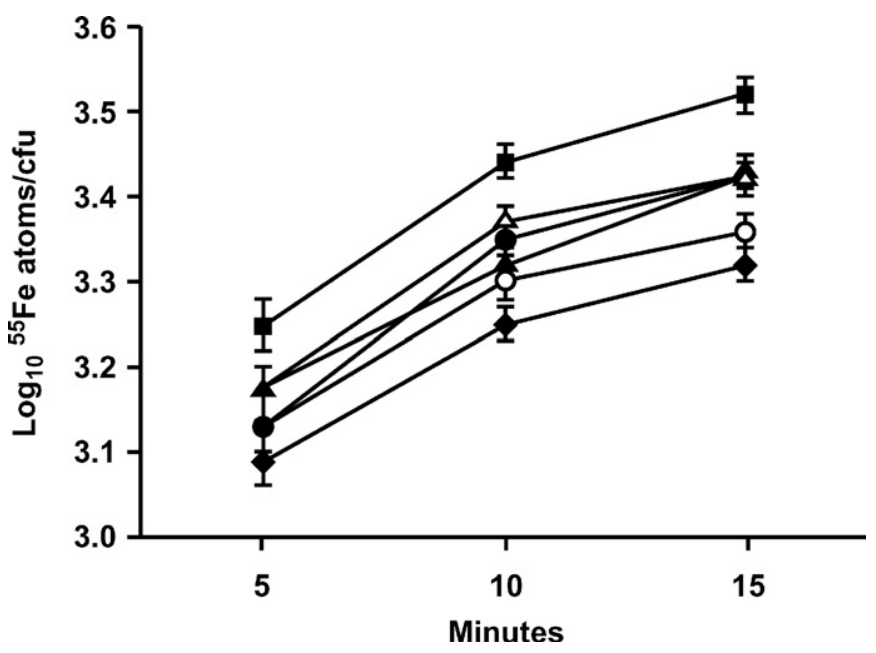

Figure 3. Mean number of ${ }^{55} \mathrm{Fe}$ atoms taken up by Escherichia coli field isolates $(\mathrm{n}=6)$ tested under conditions to selectively induce the expression of FecA. Isolates were grown in the presence of $3 \mathrm{mg} /$ $\mathrm{mL}$ of anti-FepA and $3 \mathrm{mg} / \mathrm{mL}$ of control $\mathrm{IgG}(\boldsymbol{\Lambda}), 6 \mathrm{mg} / \mathrm{mL}$ of antiFepA IgG $(\Delta), 3 \mathrm{mg} / \mathrm{mL}$ of anti-FecA and $3 \mathrm{mg} / \mathrm{mL}$ of control $\operatorname{IgG}(\bullet)$, $6 \mathrm{mg} / \mathrm{mL}$ of anti-FecA IgG (O), $3 \mathrm{mg} / \mathrm{mL}$ of anti-FepA and $3 \mathrm{mg} / \mathrm{mL}$ of anti-FecA IgG ( ), and PBS without IgG (ם). Dispersion bars represent standard errors of the mean.

pared with anti-FepA IgG alone $(P<0.01)$ and antiFecA IgG alone $(P=0.06)$ after a 5 -min incubation. The combined effects of both anti-FecA and anti-FepA IgG had greater reduction in iron transport than either treatment alone at $5 \mathrm{~min}$, but not at 10 or $15 \mathrm{~min}$.

Synergistic effects of IgG. The presence of IgG reduced iron uptake compared with $\mathrm{PBS}(P<0.01)$. Immunoglobulin $\mathrm{G}$ from immunized cows had greater reduction in iron uptake than did treatments containing control IgG $(P<0.001$; Figure 3). Treatments containing anti-FecA reduced uptake of ${ }^{55} \mathrm{Fe}$ compared with treatments containing anti-FepA after a 5-min incubation $(P<0.05)$. The synergistic effect of both anti-FecA and anti-FepA IgG caused greater reduction than any other treatment containing anti-FecA at $10(P<0.01)$ and 15 $(P<0.01) \mathrm{min}$. The synergistic effect of both anti-FecA and anti-FepA IgG caused greater reduction than any other treatment containing anti-FepA after 5-, 10-, and 15 -min incubation $(P<0.05)$. The synergistic effect of the combination of anti-FecA and anti-FepA IgG caused greater reduction in iron transport than either antibody treatment alone.

\section{DISCUSSION}

Several outer membrane proteins have been associated with specific iron transport systems for $E$. coli (Briat, 1992; Neilands, 1994). Two high-affinity iron acquisition systems are commonly used by $E$. coli that cause bovine mammary infections. Ferric enterobactin is commonly induced by $E$. coli isolated from mammary infections in iron-deficient conditions (Lin et al., 1998a). In the presence of citrate occurring at high levels $(\sim 7$ $\mathrm{m} M$ ) in the milk of lactating dairy cows (Jenness, 1974), enough ferric dicitrate complex forms to induce the citrate-dependent iron uptake system as well (Hussein et al., 1981; Lin et al., 1999a). Therefore, the ferric enterobactin and ferric citrate iron transport systems can operate simultaneously in wild-type $E$. coli cells (Frost and Rosenberg, 1973). The central hypothesis of this trial was a combination of anti-FecA IgG and antiFepA IgG would inhibit iron uptake by $E$. coli mastitis isolates in an in vitro system greater than either source of antibody alone. The hypothesis was initially tested by comparing the individual sources of IgG at $3 \mathrm{mg} / \mathrm{mL}$ with the combination at $6 \mathrm{mg} / \mathrm{mL}$ in 2 iron-depleted conditions. In general, the combination of anti-FecA IgG and anti-FepA IgG reduced iron uptake compared with either anti-FecA or anti-FepA alone when culture conditions were set for nonspecific induction of IROMP and when citrate was added to media to specifically induce the ferric citrate iron acquisition system. Iron uptake was reduced more by anti-FecA IgG than by anti-FepA when the ferric citrate system was induced. Reduction of iron uptake did not differ between antiFepA IgG alone and anti-FecA IgG alone when citrate was absent from the medium. Data from the trial comparing the synergistic effects of the combined anti-FecA $(3 \mathrm{mg} / \mathrm{mL})$ plus anti-FepA $(3 \mathrm{mg} / \mathrm{mL})$ at $6 \mathrm{mg} / \mathrm{mL}$ with each IgG source alone at $6 \mathrm{mg} / \mathrm{mL}$ supported the conclusion that the enhanced iron uptake inhibition by the combination of antibody sources was a synergistic effect and not due to higher concentration of antibody in the combination.

The FecA (Lin et al., 1999a) and FepA (Rutz et al., 1991) are highly conserved antigenic outer membrane proteins expressed by $E$. coli isolates tested in the present study (Lin et al., 1999a,b). These characteristics make them attractive candidates for vaccination against bovine mastitis-causing coliform bacteria. Immunization, yielding antibodies that block one outer membrane protein, may force the uptake through the other coinciding system. Therefore, antibodies specific for FecA and FepA further blocked iron uptake into the bacterial cells, but did not completely starve the cell of its iron requirement in vitro. The consequences of the partial denial of iron to bacteria were exemplified in earlier trials whereby IgG from cows vaccinated with FecA effectively reduced iron uptake in the in vitro assay (Takemura et al., 2003), but did not reduce total bacterial growth over constitutive antibody from unvaccinated cows (Takemura et al., 2004).

Escherichia coli can induce other iron acquisition systems including ferrichrome, ferric aerobactin, and ferric 
rhodotrulate (Briat, 1992; Neilands, 1994). In the ironstarved environment of this assay, with the major uptake systems blocked, these less common transport systems could have been induced to obtain iron. Ferric dicitrate has a molecular mass of $434 \mathrm{kDa}$, which is small enough to diffuse through channel porins (Braun, 1997; Ferguson et al., 2002). In the presence of citrate, ferric citrate complexes form, but transport through the outer membrane protein FecA is blocked by antibody. Nitrilotriacetate was added to the assay to suppress nonspecific iron transport (Takemura et al., 2003), but did not stop ferric citrate, which is small enough to pass through porin channels. This may have been another method by which $E$. coli was still able to acquire iron in this assay.

The hypothesis that the synergism of antibodies specific for FecA and FepA would reduce iron transport compared with either antibody source alone was supported in the current experiments. The current trial and a series of previous experiments (Lin et al., 1998b; 1999b; Takemura et al., 2003) have shown that the FepA and FecA proteins are antigenic to dairy cows, and that IgG from vaccinated cows reduce iron uptake and replication in vitro. Despite the presence of antibody specific to FecA and FepA outer membrane receptors on $E$. coli, these antibody sources did not completely inhibit the uptake of iron into the bacterial cell or bacterial replication. This may be attributed to nonspecific transport of iron complexes through the porin channels, the induction of other high-affinity transport systems, or the antibodies binding to areas of the IROMP that will still allow recognition of their specific iron complexes.

The cumulative results of trials on blocking iron uptake and growth of $E$. coli by bovine antibody specific for high-affinity ferric receptors indicates that this approach may not be feasible in lessening the incidence or severity of coliform mastitis. The concentrations of purified antibody used for in vitro iron uptake and growth inhibition trials conducted in minimal, defined media have exceeded the concentrations of antibody in complex mammary secretions. Likewise, experimental IMI data implied that vaccination with IROMP lacks efficacy. Although FecA-immunized cows had increased antibody titers to FecA, vaccination showed minimal effect on clinical severity of mastitis compared with nonimmunized control cows (Takemura et al., 2002). The myriad of high- and low-affinity iron acquisition systems of $E$. coli appear to allow the pathogen to acquire iron and replicate despite the presence of IgG specific for one or more IROMP.

\section{REFERENCES}

Braun, V. 1997. Surface signaling: Novel transcription initiation mechanism starting from the cell surface. Arch. Microbiol. 167:325-331.

Briat, J. F. 1992. Iron assimilation and storage in prokaryotes. J. Gen. Microbiol. 138:2475-2483.

Chart, H., and E. Griffiths. 1985. Antigenic and molecular homology of the ferric enterobactin receptor of Escherichia coli. J. Gen. Microbiol. 131:1503-1509.

Ferguson, A. D., R. Chakraborty, B. S. Smith, L. Esser, D. van der Helm, and J. Deisenhofer. 2002. Structural basis of gating by the outer membrane transporter FecA. Science 295:1715-1719.

Frost, G. E., and H. Rosenberg. 1973. The inducible citrate-dependent iron transport system in Escherichia coli K-12. Biochim. Biophys. Acta 330:90-101.

Hantke, K. 2001. Iron and metal regulation in bacteria. Curr. Opin. Microbiol. 4:172-177.

Hussein, S., K. Hantke, and V. Braun. 1981. Citrate-dependent iron transport system in Escherichia coli K12. Eur. J. Biochem. 117:431-437.

Jenness, R. 1974. The composition of milk. Pages 3-107 in Lactation: A Comprehensive Treatise. B. L. Larson and V. R. Smith, ed. Academic Press, New York, NY.

Lin, J., J. S. Hogan, M. Aslam, and K. L. Smith. 1998a. Immunization of cows with ferric enterobactin receptor from coliform bacteria. J. Dairy Sci. 81:2151-2158.

Lin, J., J. S. Hogan, and K. L. Smith. 1998b. Inhibition of in vitro growth of coliform bacteria by a monoclonal antibody directed against ferric enterobactin receptor FepA. J. Dairy Sci. 81:1267-1274.

Lin, J., J. S. Hogan, and K. L. Smith. 1999a. Antigenic homology of the inducible ferric citrate receptor (FecA) of coliform bacteria isolated from herds with naturally occurring bovine mammary infections. Clin. Diagn. Lab. Immunol. 6:966-969.

Lin, J., J. S. Hogan, and K. L. Smith. 1999b. Growth responses of coliform bacteria to purified immunoglobulin $\mathrm{G}$ from cows immunized with ferric enterobactin receptor FepA. J. Dairy Sci. 82:86-92.

Murphy, C. K., V. I. Kalve, and P. E. Klebba. 1990. Surface topology of the Escherichia coli K-12 ferric enterobactin receptor. J. Bacteriol. 172:2736-2746.

Neilands, J. B. 1982. Microbial envelope proteins related to iron. Annu. Rev. Microbiol. 36:285-309.

Neilands, J. B. 1994. Effects of iron deprivation on outer membrane protein expression. Methods Enzymol. 235:345-353.

Rutz, J. M., T. Abdullah, S. P. Singh, V. I. Kalve, and P. E. Klebba. 1991. Evolution of the ferric enterobactin receptor in gram-negative bacteria. J. Bacteriol. 173:5964-5974.

Takemura, K., J. S. Hogan, J. Lin, and K. L. Smith. 2002. Efficacy of immunization with ferric citrate receptor FecA from Escherichia coli on induced coliform mastitis. J. Dairy Sci. 85:774-781.

Takemura, K., J. S. Hogan, and K. L. Smith. 2003. Effect of immunoglobulin $\mathrm{G}$ from cows immunized with ferric citrate receptor (FecA) on iron uptake by Escherichia coli. J. Dairy Sci. 86:133137.

Takemura, K., J. S. Hogan, and K. L. Smith. 2004. Growth responses of Escherichia coli to immunoglobulin from cows immunized with ferric citrate receptor, FecA. J. Dairy Sci. 87:316-320.

Todhunter, D. A., K. L. Smith, and J. S. Hogan. 1991. Antibodies to the iron-regulated outer membrane proteins of coliform bacteria isolated from bovine intramammary infections. Vet. Immunol. Immunopathol. 28:107-115.

Zhou, X. H., D. van der Helm, and L. Venkatramani. 1995. Binding characterization of the iron transport receptor from the outer membrane of Escherichia coli (FepA): Differentiation between FepA and FecA. Biometals 8:129-136. 